\title{
The Effect of the Vitality Level of University Campuses on Increasing Social Interactions
}

\section{Saeed Azemat ${ }^{1}$,Seyed Bagher Hossini², Navid Elyasi ${ }^{3}$, Farhang Mozaffar ${ }^{2}$}

\author{
1 School of Architecture, \\ Art University of Isfahan, Iran \\ 2 School of Architecture and Environmental Design, \\ Iran University of Science \& technology, Tehran, Iran \\ ${ }^{3}$ Department of Architecture, \\ University of Tehran, Iran \\ S.Azemati@Aui.ac.ir, Hosseini@iust.ac.ir, Navid.elyasi@ut.ac.ir, F.Mozaffar@Aui.ac.ir
}

\begin{abstract}
In recent years, universities in Iran have been developed and extended, and the open spaces which help to attain the university goals have been rarely considered. This study aims at reviewing the previous landscape designing theories and approaches, which leads to making vitality in the university spaces and finally the effective parameters of vitality in university open spaces. Therefore, this study is a descriptive review of esthetic, ecological and social-cultural aspects of landscape architecture designing in the academic spaces, and as its title implies, it tries to find a way to develop the science of designing open spaces in university sites in such a way that it improves the quality of interactions in these open spaces.
\end{abstract}

Keywords: Landscape architecture; university campus; landscape social- culture aspect; ecology aspect

eISSN 2398-4295 @ 2018. The Authors. Published for AMER ABRA cE-Bs by e-International Publishing House, Ltd., UK. This is an open-access article under the CC BY-NC-ND license (http://creativecommons.org/licenses/bync-nd/4.0/). Peer-review under responsibility of AMER (Association of Malaysian Environment-Behaviour Researchers), ABRA (Association of Behavioural Researchers on Asians) and cE-Bs (Centre for EnvironmentBehaviour Studies), Faculty of Architecture, Planning \& Surveying, Universiti Teknologi MARA, Malaysia.

DOI: http://dx.doi.org/10.21834/ajbes.v3i12.133 


\subsection{Introduction}

Landscape design of academic spaces is one of the main issues. Scientific matters and theoretical approaches in design have been rarely paid attention. Academic campus is not a trade building or location for partial development. The campus is an area with buildings devoted to higher education. On one hand, definition of landscape design (creativity and art) may increase the validity of a design supported by scientific theory and create a new process in this scope on the other hand. To find out a tangible issue through focus on triple aspects of landscape design (social- cultural, ecology and aesthetics aspects) concerning landscape structure patterns. As theory of landscape relates with spatial identity (spatial approach) and spatial function (human- oriented approach) therefore, selection of landscape texture and their examination by triple aspects may result in grasping language of spatial and humanoriented patterns. By the way, appearance of human in landscape (even as element of landscape) in addition to quality of academic spaces and landscape textural values are accounted as principles of landscape design. Nature in academic spaces slightly appears without meeting specific needs of users and high capabilities of nature in this way. Necessarily, design of the university campus is executed with the aim of fulfillment of users' different demands.

We can investigate importance of nature in academic spaces by several important phases:

- Natural capabilities in classic education

- Natural capabilities in non- classic education (social development, physical growth, social interactions)

\section{- Benefiting from aesthetics and emotional aspects of nature}

2. Definition of University and Design Challenge

University is defined as an independent system founded by public investment. A group of academic administrators, professors and students who seek knowledge and develop it. Generally, a university dedicates a physical area with a sense of social identity and concentration. Some exception there are including, the Open University of England emphasize on electronic media and holding summer education for students to relate with academic concepts seriously but buildings of the university meet two functional and conceptual aspects. Since, researchers gather in universities to seek science by group so, how scientific function of different organizations is form with a specific spatial pattern is essential (Ahmad et al, 2013).

\subsection{Importance of University Campus}

Whether universities are organizational complex and physical locations but not simple places. University campus is not trading park or a place for less development, there are buildings constructed for higher education. The issue plays ruling role and ideals of university education through architecture and urban design rather than constructional developments (Campus et al., 2007). University as a place for buildings, statues, landscaping and general spaces are an artwork. It means that either university campus a conceptual work of distinguished art and reflects human- made art in making a place. The best old and new 
campuses are those that place campus but not buildings are gathered. They are surrounded, edged, with heart, sign and memorial places. Buildings are like university living background. Their functions present educational generality. Each building reflects various ideas of architecture. Buildings constructed by Rodgers, Jourda, Faoster are the first samples in this case. Systematic plan for expansion of the University of Nottingham by Hopkins introduces a similar goal in larger scale. Hence, university campus is an artwork and a place for experience and experiment (Abem, 1999).

\subsection{Application of Environmental Psychology}

General Scopes of behavioral sciences in scope of architecture of open spaces try to establish the foundation of their studies on the basis of development, learning and education theories. So, many studies seek open spaces complying with mental needs. From 1990 onwards, compound of architectural psychology and learning theories have more taken into consideration in the creation of open spaces. Researchers and designers found out interrelationship of two indices and spatial, mental, physical and behavioral fields. Change of spatial traditional patterns from closed to open patterns for education of users is the most significant achievements in this study (Achmad Delianur Nasution \& Wahyuni Zahrah, 2012). By the way, this issue like a symbol to leave spatial closed structures for students has been considered to provide familiar and multifunctional environments. Considering functional, specific, safety, environmental quality and quantity features as well as public influence of students are the main issues. Others such as, spatial direction, collective spaces, environmental information, exciting colors, relationship, spatial inflexion, transparency, memorials and so on, have been used for indicating design patterns with psychology origin in the field of architectural function. All show a situation that is repeated frequently. Some of the patterns are the small society of learning, show spaces, visual outlook, privacy spaces and social relationship (Mennat-Allah El-Husseiny, 2013). The goal is improvement of spatial qualities for effective and valuable environments considering topics of behavioral sciences in environmental design and obtaining appropriate results.

\subsection{Landscape Architecture Theories and University Colleges}

Landscape of a university site represents two- aspect background of physical and visual. Physical function belongs to such elements of accessibility of architectural closed spaces, literature of traffic, a comfort place for dialogue and open study on sites, grass flat and other related issues which are the second stance in applied architecture because of another main application. Visual and conceptual functions turn back to what exist in viewer's memory. such events have an influence when viewer observe the landscape and create conception of environment and landscape. Nowadays, many researchers of landscape architecture have been founded by this way (Abdul Aziz et at., 2012).

In this framework, two theories of landscape architecture with education- oriented approach exist. Environmental capabilities, mental background has more intervention in 
environmental conception but in mental refreshment theory, environmental factors have more emphasis but the later is criterion to describe and develop this research.

\subsection{Environmental capability theory}

This theory has been presented by James Gibson about efficiency, competence, ultra physic capabilities of environment and landscape. In his view, each element of environment has the following capabilities in addition to related function. Each element in nature has a response. Upon this theory, tree is not merely for visual enjoyment and makes shadow but feelings like climbing, grasping its branches and touching grooves of tree and relying on it, are motivated. Of course, the hypothesis is viewer's perception which turns back social, cultural, economic and religious backgrounds. Grass excites the child to wallow, student to sit and study, and adult to walk. Therefore, theory of Gibson is a psychological origin, he watch the environment although, direct perception has enrooted and interweave soul and body, texture, meaning, view and landscape with a similar nature (Lova et al., 2004). Theory of Gibson is expended that environmental capabilities is not regarded to its elements but cover human beds like culture and society whether the same origin. Because, social, cultural, economic, climatic and local factors define environmental origin. Figure 2, show relationship of human, environment and environmental capabilities. Only a part of environmental capabilities covered by human is practical and has been flourished. But many aspects remain on potential stance. Relationship of environment and human factors have been indicated in figure I. In model diagram, vertical oval change among humans with a nominal change in identical social, cultural and economic beds and their wide differences (Uribe et al., 2007).

Many researchers have been done for Gibson theory function about environmental capabilities. But much more relate to residential spaces and societies especially, children. In university environments, landscape elements of campuses promote environmental capabilities in two scientific and executive fields. Study of this theory in websites may complete this research and propose ideas in the future.

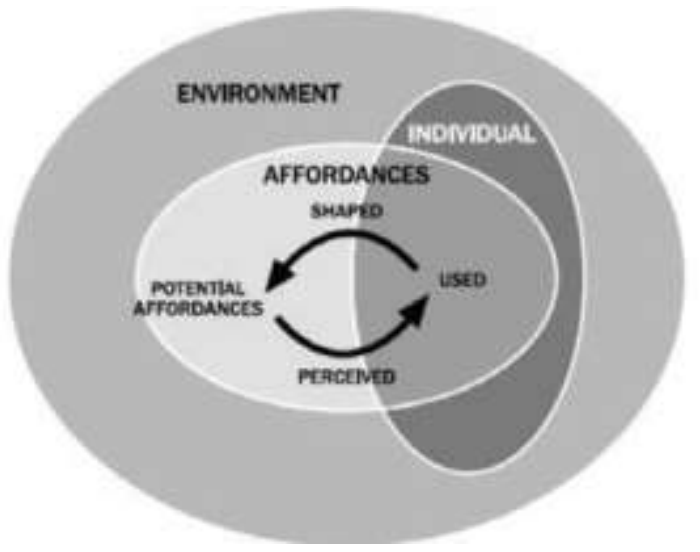

Fig. 1. The relationship of human, environment and environmental capabilities 


\subsection{Mental refreshment theory}

Upon researches of Rachel and Stephen Kaplan as founders of mental refreshment, continuous concentration such as, study and work on the table, make mind fatigue as well as mental dispersion, enhance mistake and lead irritability, impatience and lack of efficiency. Nature, parks and gardens may refresh mental fatigue. Theory of Kaplan for mental refreshment represents an appropriate applied pattern to decrease mental stress and anxiety in urban environments far from nature. Ideas of the theory have been reviewed and tried to decline its popularity and emphasize on its adjustment on landscape architecture in university campus (Hussein, 2012). The first element is being far from, free, exhilaration or leaves the place or situation which mental fatigue is occurred. Such places of coffee shop, internet salon shall be near classrooms in educational centers free from. But it may not remove longsome trend. Therefore, landscape as a capability to leave mental fatigue of students help impressively. No need for physical appearance of students in landscape but look up to the landscape behind the window of classroom or library may release the mind. To refresh mind daily affairs in many non educational environments including, offices, open site, hospitals in campuses follow the formula (Abu-Ghazzeh, 1999).

\subsection{What is Appropriate for an Attractive Landscape of University Environment?}

There are three principal components for open space of university which promote environmental quality of university.

- Physical and ecological quality , support natural characteristics of environment

- Behavioral and functional quality, support behavioral interactions and physical decoration

It involves population density and comfort to sit a place. Availability of needs such as, food and drink like interaction of adjacent buildings and its surroundings.

- Aesthetic and visual quality based on visual feelings. This is the most significant aspect of aesthetic for visual quality of greens spaces.

The most impressive factor to highlight a place is how a user understands environmental physical concepts and makes decision about quality and efficiency of landscape (Lamer, 2003).

Users are able to control their relationships and social interactions by the problem, understand characteristics of daily environments and enjoy its beauties. Understanding of a user of university landscape has been woven to her/his activities.

\subsection{New Vision to Design of University Campus}

In 1993, Armstrong pointed out that all people can make decision for different mental and social situations to rule on their life condition. He continued that better decisions are made when a person participate in decision making. He also proposed that public intervention plays a remarkable role in distinguish variety of needs and issues on the basis of Danish experiences for that ordinary residents participate in physical plans of urban design in the 
way that they act in finding solutions and options. It is concluded in explaining problems in negotiations and social discussions so, a social knowledge is made to became plans more effective and stable (Shepherd \& Patzelt, 2011).

Also, if professional designers are not familiar with related knowledge of environmental psychology, main issues of users' needs and expectations may miss.

\subsection{Community-Based Design}

During last twenty years, many users focus on university campus emphasized on active life and public spaces. Many universities redesign their open spaces or expand it while importance of social interactions is clear for them. In landscape design, concept of active life and public spaces was origin of community- based design. Table 1 indicates their comparison. First stage, show guideline to conduct project without any question about social demands fit with opinions of in charges. Community- based attitude is in another side specified before design by residents' ideas.

Table 1. Authors,traditional and community- based attitudes in design planning (PPS)

\begin{tabular}{cc}
\hline Community- based Attitude & Traditional Attitude \\
\hline Location & Project \\
Community- based & Act- oriented \\
User determine & User should adjust it \\
\hline
\end{tabular}

Figure 2 show, relationship of users, design experts opinions of traditional attitude. This attitude does not intervene design experts opinions in first stages of design.

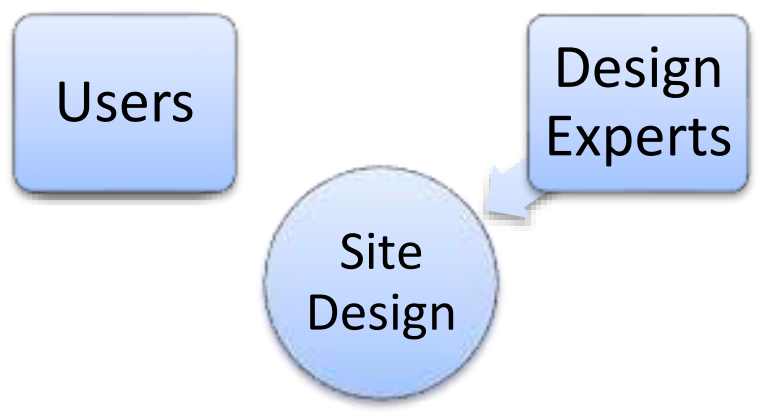

Fig. 2. Traditional design attitude 
Figure 3, community- based attitude, users intervene in design like design experts.

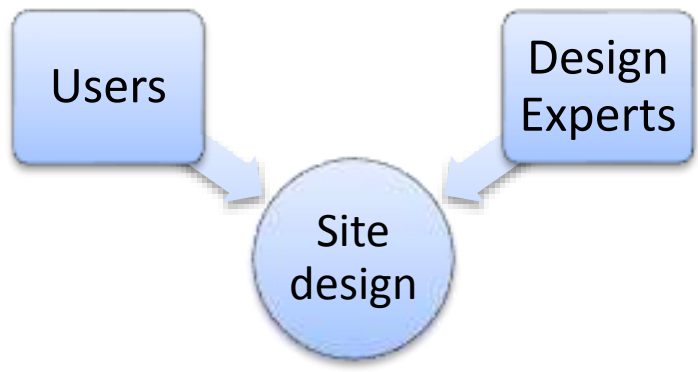

Fig. 3. Community- based design attitude

Social participation of people and students to design universities is so important. Providing many ways for social interactions of individuals, university environments create sense of community. The idea of a community for learning or places for ideas exchange with regular decoration is one of the biggest academic inventions during last years. University environment need to widespread scope of activity. The university should not be established to meet academic curriculum but a place for catalyze social interactions of students (Aziz \& Said, 2012).

\subsection{Active Life and Social Spaces}

Researchers in health have studied physical activities affected by many environmental factors. Although, many important factors have not been informed but enough evidence show that compatible environments help people more for having an active life. Active life is a way of living of which physical activities are more worthy and connect to daily life while focus on the issue that how created environment such as, locals, transportation, buildings, parks and outdoors may provide more active life. Now, colleges emphasize on significance of active life in university campus. Campus in some colleges are redesigned to adjust principles of active life including,

- Walking in campus, comfort walking and corridor open space

- Safe vehicles transportation on pavements and streets for complementary of environment and criterion for pedestrians traffic, if requires

- Corridor for pedestrians with convenience and continuity elements

- Continuity of types of pavements

- Concrete patterned pavements which repair easily. Specific bricks or asphalt materials should be used in limited certain places. To replace, concrete floor is applicable. Another 
floor covering are ugly and dangerous at the time of replacement. Concrete floor is constructed in human scale and various patterns.

- More emphasis on comfort, cleanness and safe and easy to use greensward

- Comfortable furniture and benches to study outside, roofed and guarded places for ordinary meetings

- Suitable and calm meeting spaces

- Eliminating nonemergency preventives

- Providing treed pathway between pedestrian and its edge, particularly margin streets of university

How landscape of university campus is designed is more essential to improve active life. Whether life patterns and guides exist but sometimes many university campuses are empty. Theses spaces are not designed for inviters. Moreover, if a state university is open and accessible for the public, it may lead improve relationship of city and university (Ujang, 2012). Urban state universities are responsible to provide an open space which is applicable and accessible. Universities and designers find out significance of integration of university campus and society as well as creation a space for students to fulfill social outdoor activity. Urban state university has been applied as a model nowadays. As a public institution, it must provide an open space to be used by the people. By the way, there are visitors allocated to their environments.

\subsection{Methodology}

In this section, the data are analyzed using the scientific methods. The purpose of collecting and classifying the obtained data from the questionnaire is to identify the variables and the relationships between them to have an appropriate conclusion. Data analysis is carried out in two phases. In the first phase, the collected data are described. The descriptive statistics is used in order to arrange the data. Thus, the study data are shown in the related tables. In the second phase, data are analyzed based on the statistical inference. The purpose of the inferential statistics is to conclude for the properties of the population from which the intended sample is derived. In the current study, analyses are performed through using SPSS software and considering the essence of the research questions, the proper statistical test of exploratory factor analysis and the single group $t$ test are used.

\section{Data analysis and results}

Table 2 shows the frequency distribution of answers' acceptance of the multi-functionality of the university space.

According to the information presented in the table and the figure 6 it can be perceived that 9 percent of students showed a low acceptance of the multi-functionality of the university space, 61 percent showed a medium acceptance and 14 percent showed a high acceptance. The above information shows that $94 \%$ of the students accept the multi-functionality as one of the most important factors of increasing the individuals' participations in the university spaces and also increasing the sense of place. 
Table 2. Authors, shows the frequency distribution of answerers

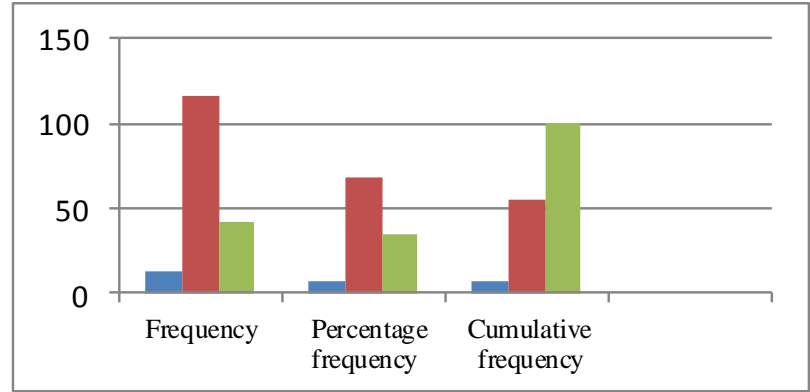

\begin{tabular}{cccc}
\hline $\begin{array}{c}\text { Acceptance } \\
\text { range }\end{array}$ & Frequency & $\begin{array}{c}\text { Percentage } \\
\text { frequency }\end{array}$ & $\begin{array}{c}\text { Cumulative } \\
\text { frequency }\end{array}$ \\
\hline low & 18 & 9 & 10 \\
medium & 102 & 61 & 66 \\
high & 58 & 14 & 105 \\
\hline
\end{tabular}

Fig. 6. The frequency distribution of answerers' acceptance of the multi-functionality of the university space

\subsection{Conclusions}

Nowadays, mental fatigue cannot be ignored in university environments with full of books, internet and information result in. Sitting behind the desk to study continuously may cause mental fatigue and increase lack of focus as well as distraction, impatience, mistake and efficiency loss. Mental fatigue may be improved by conscious configuration elements of landscape in university campus. Hence, conscious configuration elements of landscape in nature, parks and university campus should be widely surveyed in two fields of scientific and executive in views of psychology and environmental studies so that concentration is rebuilt. On the other hand, state universities are public institutions and should be public and available, because it helps relationship of city and university. If the people are comfort to enter into campus, more safe relationship is existed.

Universities and designers understand two points for updating and expanding main map of universities in present date. First, importance of campus and society integration and second, creation of places for social outdoor activities for students there are. The third point, a space for social outdoor activities for the public, which has not been regarded. Some spaces are attractive for students but not for the people due to its situation, character and its quality. Some universities believe that open spaces of universities are suitable for the people. Indeed, they are attractive for being a place for tourism or visit. It is not sufficient to integrate 
campus and society. They are responsible to create places in campus to be used for social outdoor activities for the public. The idea mentioned here is, an appropriate outdoors lead to development of social outdoor activities while size of universities is so important. Therefore, significance of participation to create such spaces provides socialization but reinforce capabilities of environments to the principal goal, education.

\section{References}

Campus, G. V., Farace, F., Rubino, C., \& Sanna, M. P. (2007). A technical refinement to prevent supratip deformity in aesthetic rhinoplasty: "the trapezoid peak". Aesthetic Plast Surg, 31(1), 88-93. doi: 10.1007/s00266-006-0153-1

Abern, J. 1999 Integration of landscape ecology and landscape design: An evolutionary process. In Issues in Landscape Ecology . pp. 119-123. Edited by J.A. Wines and M.R. Moss. International Association for Landscape Ecology, Guelph, Ontario, Canada.

Lova, P., Campus, F., Lombardi, R., Cattaneo, M., Sinigaglia, F., Balduini, C., \& Torti, M. (2004). Contribution of protease-activated receptors 1 and 4 and glycoprotein $\mathrm{Ib}-\mathrm{IX}-\mathrm{V}$ in the $\mathrm{G}(\mathrm{i})$-independent activation of platelet Rap1B by thrombin. J Biol Chem, 279(24), 25299-25306. doi: 10.1074/jbc.M313199200

Uribe, M., Hunter, B., Gonzalez, G., Jorquera, M., Salazar, G., Salas, S., . . Campusano, E. (2007). Family interactions of liver transplanted children: are they normal. Transplant Proc, 39(3), 615-616. doi: 10.1016/j.transproceed.2006.12.033

Abu-Ghazzeh, T. M. (1999). "Communicating behavioral research to campus design:factors affecting the perception and use of outdoor spaces at the University of Jordan."Environment and behavior, vol. 31, no. 6, pp. 764-804, Nov 1999.

Lerner, J. (2003). Learning disability: Theories, diagnosis, and teaching strategies. Boston, MA: Houghton Mifflin.

Shepherd, D. A., \& Patzelt, H. (2011). The New Field of Sustainable Entrepreneurship: Studying Entrepreneurial Action Linking 'What Is to Be Sustained' With 'What Is to Be Developed'. [Article]. Entrepreneurship: Theory \& Practice, 35(1), 137-163. doi: 10.1111/j.1540-6520.2010.00426. 